\title{
Rainfall Reliability Evaluation for Stability of Municipal Solid Waste Landfills on Slope
}

\author{
Fu-Kuo Huang, ${ }^{1}$ Grace S. Wang, ${ }^{2}$ and Yueh-Lin Tsai ${ }^{3}$ \\ ${ }^{1}$ Department of Water Resources and Environmental Engineering, Tamkang University, New Taipei City 25137, Taiwan \\ ${ }^{2}$ Department of Construction Engineering, Chaoyang University of Technology, Taichung City 41349, Taiwan \\ ${ }^{3}$ Project Department, GeoTech Science Corporation Ltd., New Taipei City 22103, Taiwan \\ Correspondence should be addressed to Fu-Kuo Huang; fkhuang@mail.tku.edu.tw
}

Received 5 November 2012; Revised 12 February 2013; Accepted 28 February 2013

Academic Editor: Sunghwan Kim

Copyright (C) 2013 Fu-Kuo Huang et al. This is an open access article distributed under the Creative Commons Attribution License, which permits unrestricted use, distribution, and reproduction in any medium, provided the original work is properly cited.

\begin{abstract}
A method to assess the reliability for the stability of municipal solid waste (MSW) landfills on slope due to rainfall infiltration is proposed. Parameter studies are first done to explore the influence of factors on the stability of MSW. These factors include rainfall intensity, duration, pattern, and the engineering properties of MSW. Then 100 different combinations of parameters are generated and associated stability analyses of MSW on slope are performed assuming that each parameter is uniform distributed around its reason ranges. In the following, the performance of the stability of MSW is interpreted by the artificial neural network (ANN) trained and verified based on the aforementioned 100 analysis results. The reliability for the stability of MSW landfills on slope is then evaluated and explored for different rainfall parameters by the ANN model with first-order reliability method (FORM) and Monte Carlo simulation (MCS).
\end{abstract}

\section{Introduction}

The response of municipal solid waste (MSW) landfills during earthquakes has gained much attention during the past years (Anderson and Kavazanjian [1], Anderson [2], Augello et al. [3], Idriss et al. [4], Kavazanjian and Matasovic [5], Kavazanjian et al. [6], Krinitzsky et al. [7], and Pinto [8]). However, there were many failure events of MSW landfills on slope resulted from rainfall situations (Huvaj-Sarihan and Stark [9], Liu [10]). Thus, the stability of MSW landfills on slope due to rainfall infiltration is another important topic worthy of further studied.

As to stability evaluation of MSW landfills on slope, safety factors are common used in engineering practice. The critical state of failure is usually regarded as reached when the factor of safety, FS, is equal to 1.0 based on this approach. This deterministic approach not only does not consider the influence of randomness and uncertainties of soil properties, analysis model, and associated parameters on the analysis results but also has not any implications about the failure probability of the critical state according to the factor of safety. In other words, factors of safety are usually selected based on past experience empirically. The relationship between the factor of safety and the probability of failure is often unclear and needs to be established. If uncertainties of associated analysis parameters are greater than anticipated, an unstable situation of the MSW landfills may be encountered by using the deterministic factor-of-safety approach. Conversely, overdesigning can probably be done to some extent when uncertainties are smaller than anticipated. Accordingly, the reliabilitybased design (RBD) or performance-based design (PBD) approach that can evaluate the ultimate or serviceability performance of the MSW landfills on slope probabilistically is preferred in landfill and slope engineering.

The researches of reliability in geotechnical engineering are growing rapidly in these years. H. D. Lin and C. P. Lin [11] applied it to drilled piles while Shou and Chen [12] to spatial risk analysis of landslide. For deep excavation, Tang et al. [13] first performed a reliability analysis and design of braced excavation systems with FOSM method. Low [14] adopted FORM and MCS method by spreadsheet to reliability-based design for retaining walls using explicit 
performance function. Owing to the performance function which is usually implicit in geotechnical engineering, Goh and Kulhawy [15] thus introduced artificial neural network to model the limit state surface of displacements for reliability analysis.

This paper will explore the application of artificial neural network to reliability analysis for rainfall stability of MSW landfills on slope. After modeling the limit state surface of concerned response parameters (factor of safety, FS) obtained from finite element program executed in this study, ANNbased FORM and ANN-based MCS are then performed to assess the reliability of rainfall stability of MSW landfills on slope. Emphasis is focused on the influence of rainfall characteristics, such as rainfall intensity, duration, and pattern on the reliability.

\section{Reliability Analysis Method}

2.1. Performance Function and Reliability. The reliability of an engineering system is defined as the probability of performing its intended function or mission (Ang and Tang [16]). The probability will depend on the properties of the system and the requirements of the level of performance. If we define a performance function, or state function,

$$
g(\mathbf{X})=g\left(X_{1}, X_{2}, \ldots, X_{n}\right)
$$

where $\mathbf{X}=\left(X_{1}, X_{2}, \ldots, X_{n}\right)$ is a vector of design variables of the system. The performance or state of the system will be determined by the function $g(\mathbf{X})$. Thus, the "limit-state" of the system may be defined as $g(\mathbf{X})=0$. If $g(\mathbf{X})>0$ stands for the "safe state", $g(\mathbf{X})<0$ will be the "failure state" or "unsatisfactory performance state."

Geometrically, the limit-state function, $g(\mathbf{X})=0$, is an $n$-dimensional surface that represents the "failure surface". If the joint probability density function of the design variables $X_{1}, X_{2}, \ldots, X_{n}$ is $f_{X_{1}, \ldots, X_{n}}\left(x_{1}, \ldots, x_{n}\right)$, abbreviated as $f_{\mathbf{X}}(x)$, the probability of the failure state of the system would be the corresponding volume integral over the failure region $g(\mathbf{X})<0[16]:$

$$
P_{f}=\int_{g(\mathbf{X})<0} f_{\mathbf{X}}(x) d x
$$

To evaluate the previous equation is generally a formidable task, especially, when the failure surface cannot be represented by explicit function. The practical methods for evaluating $P_{f}$ are often those of FOSM, FORM, or MCS, in which the failure probability, $P_{f}$, is estimated by reliability index in FOSM:

$$
\beta=\frac{\mu_{g}}{\sigma_{g}}
$$

where $\mu_{g}$ and $\sigma_{g}$ are mean and standard deviation of the performance function $g(\mathbf{X})$, respectively. Based on the definition, the $\beta$ value may be different for two equivalent performance functions in FOSM, and thus restrict its usage. For
FORM Ditlevsen [17] uses the matrix formulation of HasoferLind index [18], another interpretation of reliability index:

$$
\boldsymbol{\beta}=\min _{X \in F} \sqrt{(\mathbf{X}-\boldsymbol{\mu})^{T} \mathbf{C}^{-1}(\mathbf{X}-\boldsymbol{\mu})}
$$

or, equivalently (Low [14]),

$$
\boldsymbol{\beta}=\min _{X \in F} \sqrt{\left(\frac{\mathbf{X}_{i}-\boldsymbol{\mu}_{i}}{\boldsymbol{\sigma}_{i}}\right)^{T} \mathbf{R}^{-1}\left(\frac{\mathbf{X}_{i}-\boldsymbol{\mu}_{i}}{\boldsymbol{\sigma}_{i}}\right)},
$$

in which $\mathbf{X}$ is a vector representing the set of random variables $\mathbf{X}_{i}, \boldsymbol{\mu}$ is the vector of mean values $\boldsymbol{\mu}_{i}, \mathbf{C}$ is the covariance matrix, $\mathbf{R}$ is the correlation matrix, $\boldsymbol{\sigma}_{i}$ is the standard deviation, and $F$ is the failure domain (i.e., $g(\mathbf{X})<0$ region). It is worthwhile to note that the variables $\mathbf{X}$ must follow the normal distributions. Otherwise, a transformation, such as R \& F method (Rackwitz and Flessler [19]), must be carried out. If $\mathbf{X}$ follows normal distributions and the performance function is linear, the failure probability, $P_{f}$, can be estimated by

$$
P_{f}=\Phi(-\beta)
$$

and approximated otherwise, in which $\Phi$ is the cumulative distribution of the standard normal variate.

Low [14] has shown that the quadratic form of reliability index $\beta$ (4b) in the original space of the variables may be interpreted geometrically as the perspective of an ellipsoid. For two-dimensional case, the quadratic form is an ellipse. As shown in Figure 1, the reliability index $\beta$ is the axis ratio $(R / r)$ of the ellipse that touches the limit state surface $(\beta$ ellipse) and the one-standard-deviation dispersion ellipse [14]. The design point, being the first point of contact between the expanding ellipsoid and the limit state surface, is the most probable failure point with respect to the safe mean-value point at the center of the expanding ellipsoid. The ellipsoidal method can be used to perform the minimization and determine $\beta$. This optimization process will be efficiently carried out in a spreadsheet environment such as Microsoft Excel [14]. It does not involve the complicated iteration procedure and dose not need coordination transformation. Thus, the method will be used in the following reliability analysis.

2.2. Approximator of the Implicit Response of System. Though Monte Carlo simulation is a powerful tool for reliability analysis, it will be too computationally extensive when the performance of the system cannot be represented by an explicit expression and need numerical analyses, such as finite element method (FEM), to evaluate its response. The explicit expression of the system response is also necessary for FORM. Thus, many researchers utilize the response surface model or artificial neural network [20] as an alternative to improve the modeling of the performance function (Box and Darper [21]; Goh and Kulhawy [15]). ANN is a special form of response surface and possesses many advantages. It will be used as the universal approximator of the implicit rainfall stability of MSW landfills on slope system in this study. 


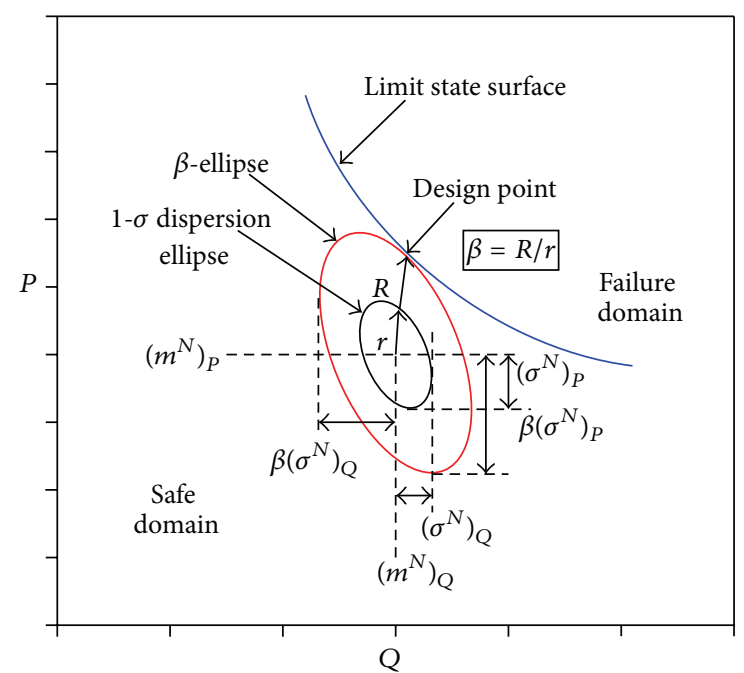

FIGURE 1: Relationship between 1- $\sigma$ dispersion ellipse, $\beta$-ellipse, and reliability index $\beta$ [14].

2.3. Procedures of the Reliability Analysis. The procedures of the reliability analysis for rainfall stability of municipal solid waste landfills on slope are shown in Figure 2. It includes the following seven steps: (1) identification of failure modes due to rainfall infiltration of MSW landfills on slope; (2) determination of design variables and its statistical properties; (3) preparation of training patterns and validation patterns for ANN inputs; (4) numerical analysis (e.g., FEM) of rainfall stability of MSW landfills on slope; (5) determination of ANN topology, and training and validation of ANN; (6) definition of performance function or limit state function; and (7) reliability analysis by FORM or MCS.

\section{Safety Requirements of MSW Landfills on Slope and Analysis Method}

After studying the failure modes of MSW landfills on slope (Bagchi [22]), it is found out that the internal rotational (circular) failure of solid waste and translational (block) failure along the liner interface are the two most common failure modes, which will be considered in this research. If factor of safety against rotational slide is denoted by $\mathrm{FS}_{c}$ and against translational failure is denoted by $\mathrm{FS}_{t}$, the final governing factor of safety of MSW landfill against failure (FS) is determined by the following formula and shown as Figure 3:

$$
\mathrm{FS}=\min \left(\mathrm{FS}_{c}, \mathrm{FS}_{t}\right) .
$$

Though landfill covers were designed to prevent or control the infiltration of precipitation into the waste, some imperfections or disrupted will let the covers lose its function. Rainfall infiltration to MSW landfill will lead it to unstable situations. In Taiwan, the minimum requirement of factor of safety against slope failure under storm circumstances is FS $\geq$ $1.20[23]$.

The stability of MSW landfill on slope affected by rainfall has close relationship to the seepage pressure in response to

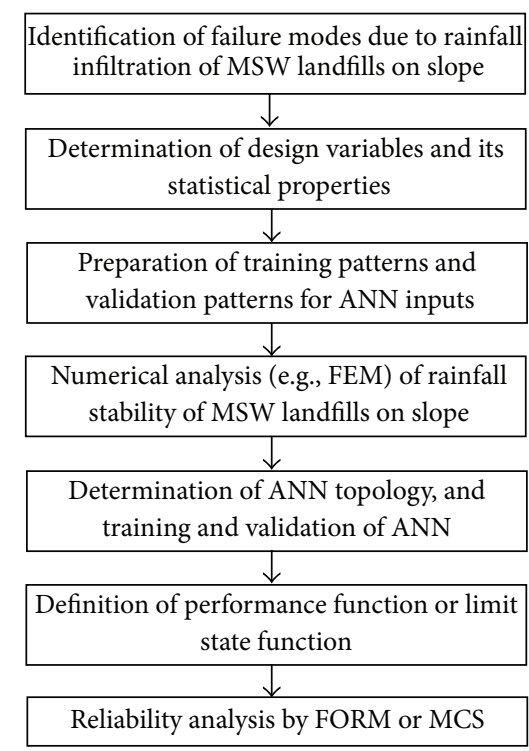

FIGURE 2: Flowchart of reliability analysis.

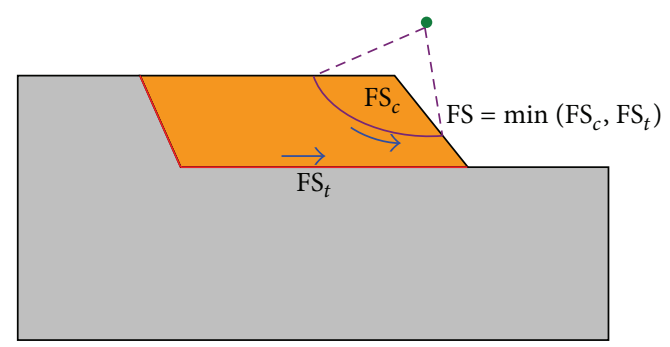

FIGURE 3: Failure modes of MSW landfills considered in this research and associated factor of safety against failure.

rainfall scenarios and related geological and geomorphologic conditions, physical and mechanical parameters. In this research, there will include both seepage analyses and slope stability analyses. The commercial finite element softwareGeoStudio package of a coupled hydrological slope stability modeling tool will be used. The SEEP/W (GEO-SLOPE International Ltd. [24]) of the GeoStudio package is used to investigate how seepage will occur in a slope under different rainfall conditions, whereas SLOPE/W (GEO-SLOPE International Ltd. [25]) can be used to study the effect of different seepage conditions (as predicted by SEEP/W) on the factor of safety of the MSW landfill on slope. SEEP/W adopts an implicit numerical solution to solve Darcy's equation for saturated and unsaturated flow conditions, describing porewater pressure and movement patterns within porous materials over space and time. The results obtained from seepage modeling can be directly linked into SLOPE/W, a limit equilibrium slope stability model, where the factor of safety is computed with the Morgenstern-Price method in this study.

In the analyses of SEEP/W, the permeability function, soil-water characteristic (SWC) curve, boundary flux, and initial hydraulic head are defined appropriate for the situations of MSW landfills on slope in advance. 


\section{Case Study of a Hypothetical Site}

4.1. Description of the Hypothetical Site. Now, a hypothetical site that may exist in real-world situations subject to rainfall infiltration, as shown in Figure 4, is illustrated as an example for reliability analysis of the rainfall stability of MSW landfills on slope. The representative values of the parameters for the hypothetical site are shown in Table 1. These factors include the geometry and material properties of MSW landfills, including height of landfill $(H)$, length of landfill $(L)$, slope angle of the back $(\alpha)$, and slope angle of the waste body $(\beta)$; and unit weight of waste $\left(\gamma_{1}\right)$, unit weight of geomembrane $\left(\gamma_{2}\right)$, unit weight of soft rock $\left(\gamma_{3}\right)$, cohesion of waste $\left(c_{1}\right)$, cohesion of geomembrane $\left(c_{2}\right)$, cohesion of soft rock $\left(c_{3}\right)$, friction angle of waste $\left(\phi_{1}\right)$, interfacial friction angle of geomembrane $\left(\phi_{2}\right)$, and friction angle of soft rock $\left(\phi_{3}\right)$. The properties of soft rock are drawn from Wang [26]. As to the rainfall characteristics that will be considered, it contains rainfall intensity $(I)$, rainfall duration $(T)$, and rainfall pattern $(\mathrm{RP})$.

4.2. Analyses of the Rainfall Stability of MSW Landfills on Slope. According to the analysis method aforementioned, coupled SEEP/W-SLOPE/W analyses have been employed to evaluate the rainfall stability of MSW landfills on slope. The rainfall patterns considered here include seven types shown in Table 2: uniform, peak at the first section, peak at the first quarter section, peak at center, peak at the third quarter section, peak at the last section, and double peak. Different rainfall patterns can be assigned in analyses by specified associated function of water unit flux versus time over the top surface boundary of the model shown in Figure 4 in SEEP/W software [24].

After parametric study, it revealed that the interfacial friction angle of geomembrane $\left(\phi_{2}\right)$ and height of landfill $(H)$ had major influences on the rainfall stability of MSW landfills. Although other factors have minor influences on slope stability relative to $\phi_{2}$ and $H$, all the parameters except for those of soft rock shown in Table 1 will be used as design variables for reliability analysis in the following.

\subsection{Training and Validation of the Artificial Neural Network} $(A N N)$. The factor of safety against slope failure is highly dependent on the geometry and material properties of MSW landfills and rainfall characteristics. The artificial neural network can provide a mapping relationship between these associated parameters. Considering the important factor that influences the stability or performance of the MSW landfills, thirteen parameters shown in Figure 5 are selected as the input neurons of the network. On the other hand, the factor of safety against slope failure, FS, from (6) is selected as the output neuron of the network.

The number of sampling points required to accurately model the mapping function of ANN is dependent on the number of design variables and the nonlinearity of the problem considered. In this paper, 100 sampling points were first randomly generated for each design variable (i.e., the 13 input neurons) assuming that it is uniform distributed around its reason range shown in Table 3. In the following, 100 data
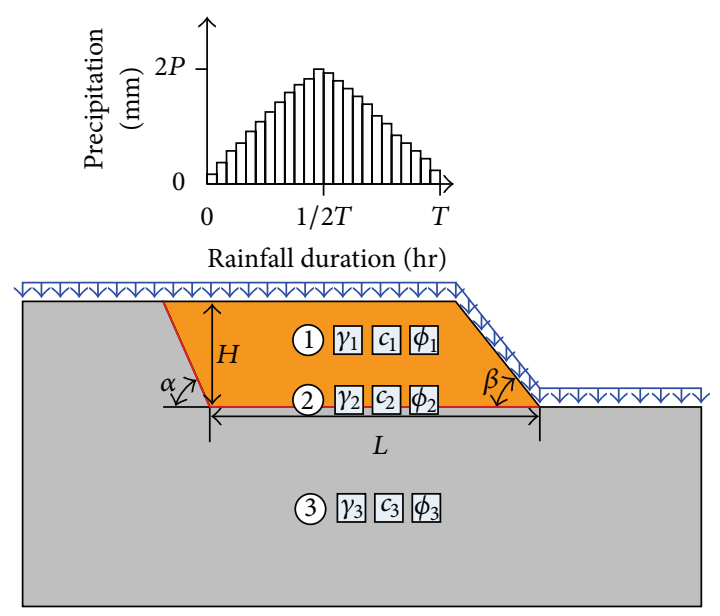

FIgURE 4: The hypothetical site and associated analysis parameters.

TABLE 1: Representative values of the parameters for the hypothetical site of MSW landfill on slope.

\begin{tabular}{lcc}
\hline Parameter type & Name & Value \\
\hline \multirow{4}{*}{ Geometry parameter } & $H(\mathrm{~m})$ & 20 \\
& $L(\mathrm{~m})$ & 30 \\
& $\alpha\left(^{\circ}\right)$ & 60 \\
& $\beta\left(^{\circ}\right)$ & 30 \\
\hline & $\gamma_{1}\left(\mathrm{kN} / \mathrm{m}^{3}\right)$ & 7 \\
$\gamma_{2}\left(\mathrm{kN} / \mathrm{m}^{3}\right)$ & 20 \\
& $\gamma_{3}\left(\mathrm{kN} / \mathrm{m}^{3}\right)$ & 24 \\
Material parameter & $c_{1}(\mathrm{kPa})$ & 34 \\
& $c_{2}(\mathrm{kPa})$ & 0.35 \\
& $c_{3}(\mathrm{kPa})$ & 245.25 \\
& $\phi_{1}\left({ }^{\circ}\right)$ & 35 \\
$\phi_{2}\left({ }^{\circ}\right)$ & 23 \\
& $\phi_{3}\left({ }^{\circ}\right)$ & 0 \\
\hline
\end{tabular}

sets are obtained from the combinations of these sampling points and then used to evaluate the corresponding value of FS by performing the coupled SEEP/W-SLOPE/W analyses. These 100 patterns including input and output are divided into two parts, each with 75 and 25 patterns, to train and validate the artificial neural network.

Analyses of ANN in this paper are based on the popular back-propagation neural network algorithm (Goh and Kulhawy [15]) for demonstration, whereas other newer learning algorithm like extreme learning machine (ELM) [27-29] may also be used in such applications. The topology of ANN in this case is shown in Figure 5, with 13 input neurons, 14 hidden neurons, and 1 output neuron. After suitable training, the mapping function of the implicit response of the MSW landfills on slope is well established. It can be seen from the scatter diagram of Figure 6 that the relationship between network outputs and training targets for variable FS in the recalling phase, using the separate 25 patterns, is almost linear. Its coefficient of determination, $R^{2}$, is greater than 0.9 . Thus, the generalization capabilities of the trained network 


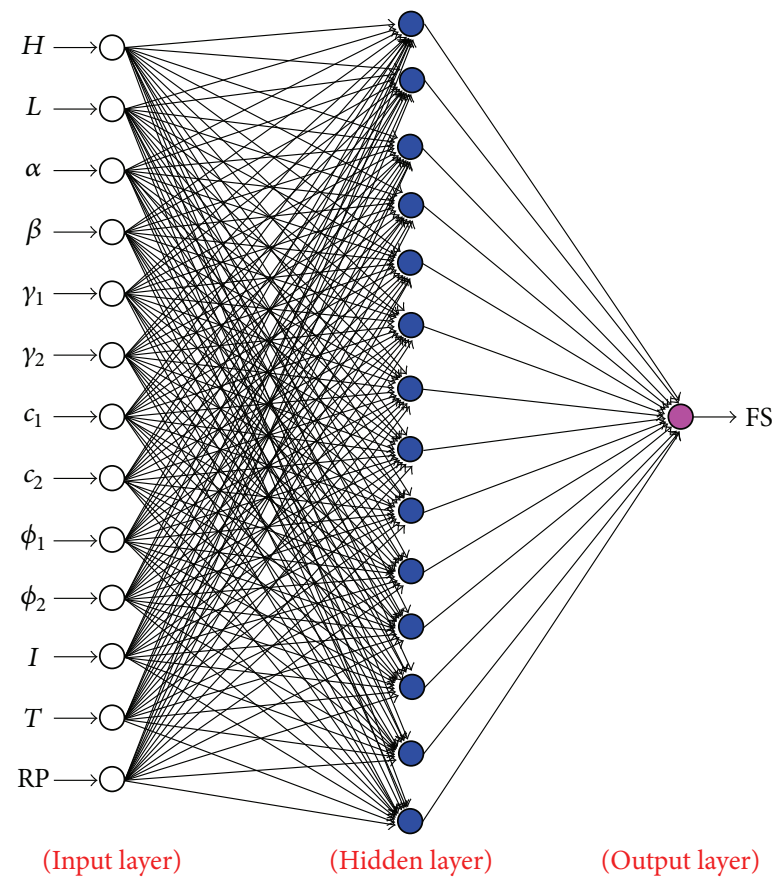

FIGURE 5: ANN topology in the case of MSW landfill on slope.

are validated. Therefore, the trained ANN can be used as a universal approximator of the implicit response (i.e., factor of safety against slope failure, FS) of the MSW landfills on slope that relates the parameters of output and input and can be employed in the following reliability analysis.

4.4. Definition of Performance Function or Limit State Function. The performance function is defined before reliability analysis for the rainfall stability of MSW landfills on slope:

$$
g(\mathbf{X})=\mathrm{FS}\left(X_{1}, X_{2}, \ldots, X_{n}\right)-\mathrm{FS}_{r},
$$

where $X_{1}, X_{2}, \ldots, X_{n}$ are design variables. $\mathrm{FS}\left(X_{1}, X_{2}, \ldots\right.$, $\left.X_{n}\right)$ is FS determined from the trained ANN given a data set of $X_{1}, X_{2}, \ldots, X_{n} . \mathrm{FS}_{r}$ is the required factor of safety against slope failure corresponding to the requirement for code or a certain limit state.

The statistical properties for reliability analysis of the thirteen parameters of ANN input neurons are shown in Table 4. Mean values $\mu$ drawn from Table 1 are regarded as the best estimated values of these parameters. Mean rainfall intensity and duration are assumed to be $I=50 \mathrm{~mm} / \mathrm{hr}$ and $T=36 \mathrm{hr}$, respectively. The values of coefficient of variation $(\mathrm{COV})$ are partly from the suggestions of Phoon and Kulhawy [30] and Duncan [31], and partly from writers' experience. Thus, the standard deviation is easily obtained from the mean value and corresponding COV.

4.5. Reliability Analysis: Monte Carlo Simulation (MCS). The reliability analysis evaluated by ANN-based MCS is illustrated first. The percentage errors of the results of the Monte Carlo simulations can be calculated by (8) (Shooman

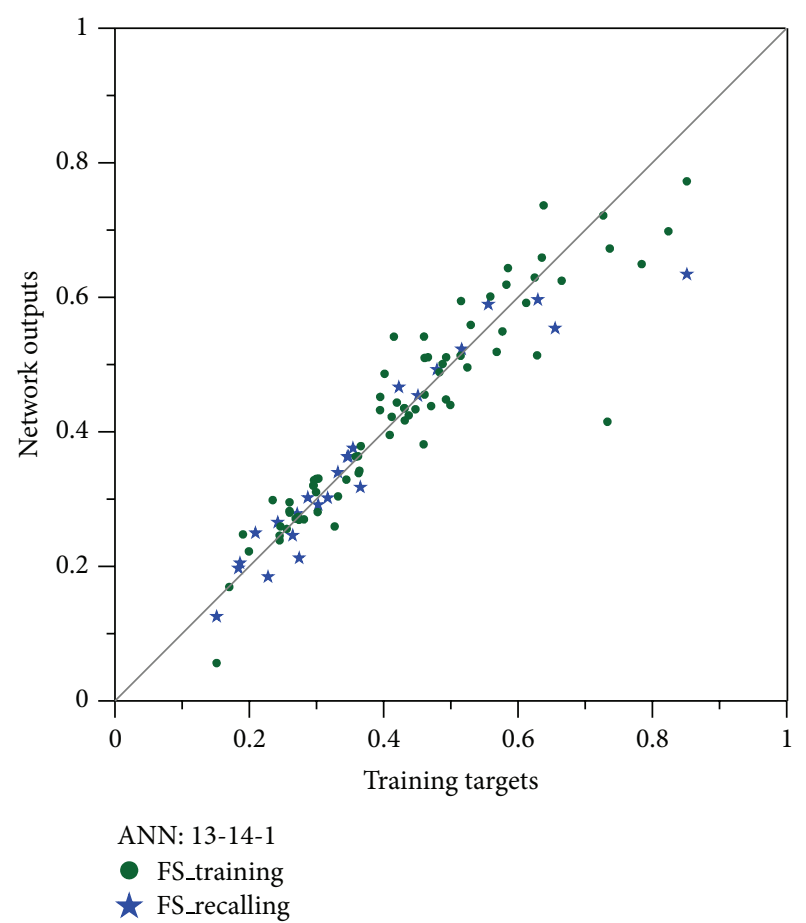

FIGURE 6: Scatter diagram of network outputs versus training targets in the recalling phase.

[32]), which is based on the $95 \%$ confidence interval for the probability of unsatisfactory performance:

$$
\% \text { error }=200 \sqrt{\frac{1-P_{f}}{N_{M} P_{f}}},
$$

where $N_{M}$ is the total number of Monte Carlo trails. For example, if $N_{M}=600,000$ and $P_{f}=0.001$, (8) then yields $8.2 \%$ error. Therefore it is $95 \%$ likely that the actually failure probability will be within $0.001 \pm 0.000082$. Since the error is relatively small, the number 600,000 will be used in this study.

Reliability of MSW landfills on slope is assessed first based on the assumptions that the input variables shown in Table 4 are all following normal distribution $N(\mu, \sigma)$, and the Uniform rainfall pattern shown in Table 2 is adopted. The input variables are supposed to be independent each other. The histogram of factor of safety (FS) obtained from MCS is shown in Figure 7. As depicted, the distribution of FS is close to normal distribution also. The mean value of FS is 1.732. Once the required factor of safety, $\mathrm{FS}_{r}$, is specified, the associated failure probability, $P_{f}=P\left[\mathrm{FS}<\mathrm{FS}_{r}\right.$ ], can be calculated immediately. Figure 8 is the analysis results for both normal and log-normal input variables for different required factors of safety $\mathrm{FS}_{r}$.

It is apparent that the failure probability $P_{f}$ is both from small to large when required factor of safety $\mathrm{FS}_{r}$ becomes larger for input variables with normal or log-normal distribution. It is a reasonable trend regarding to the practical application. 
TABLE 2: The pattern type of rainfall.

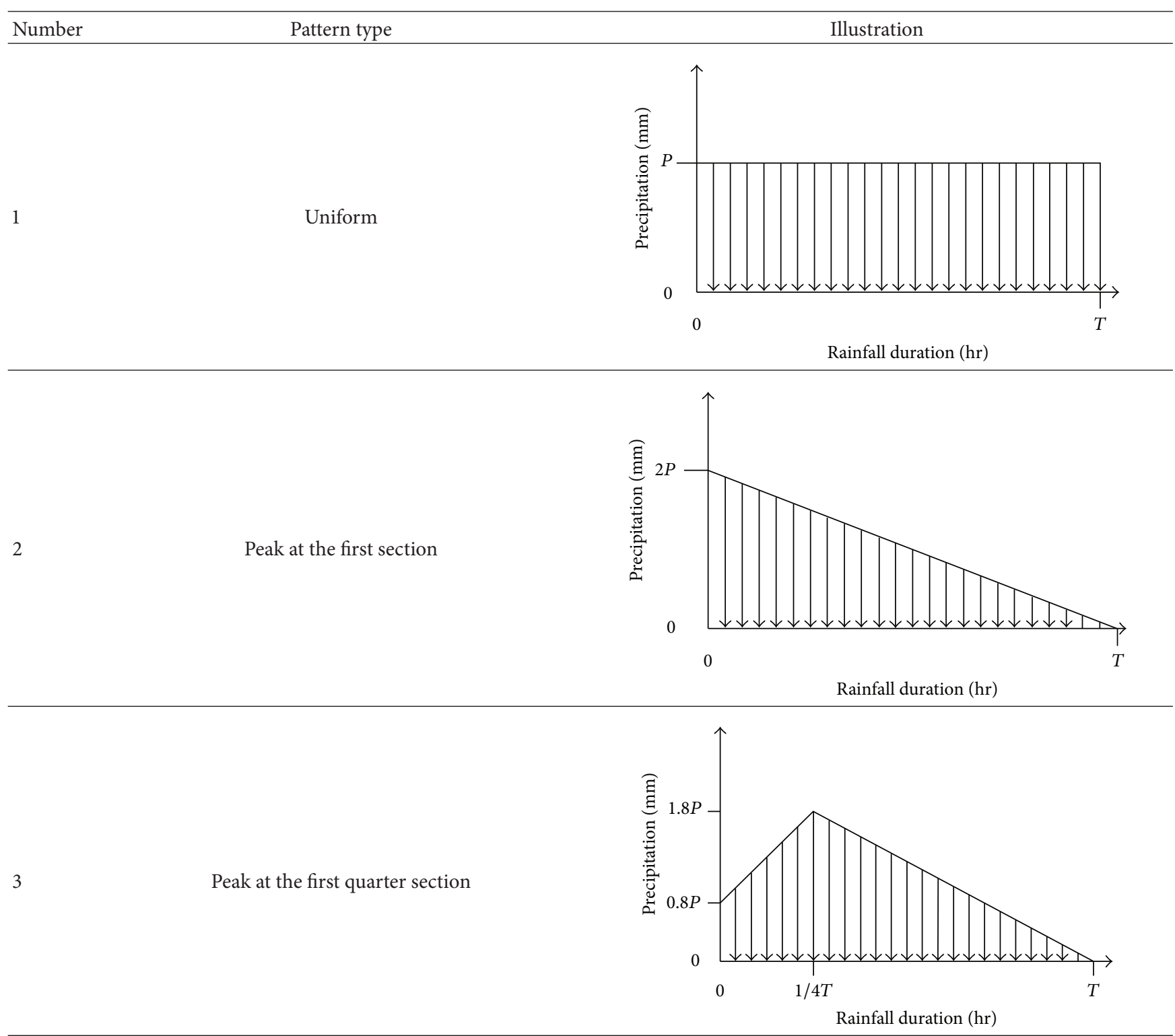

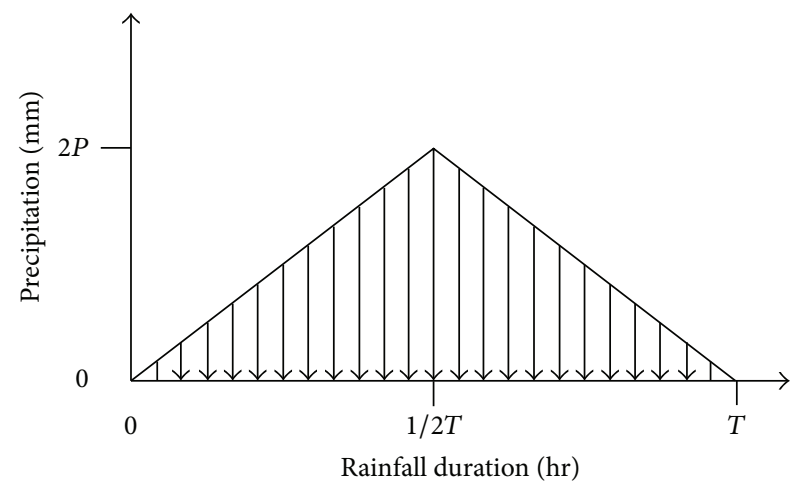


TABLE 2: Continued.

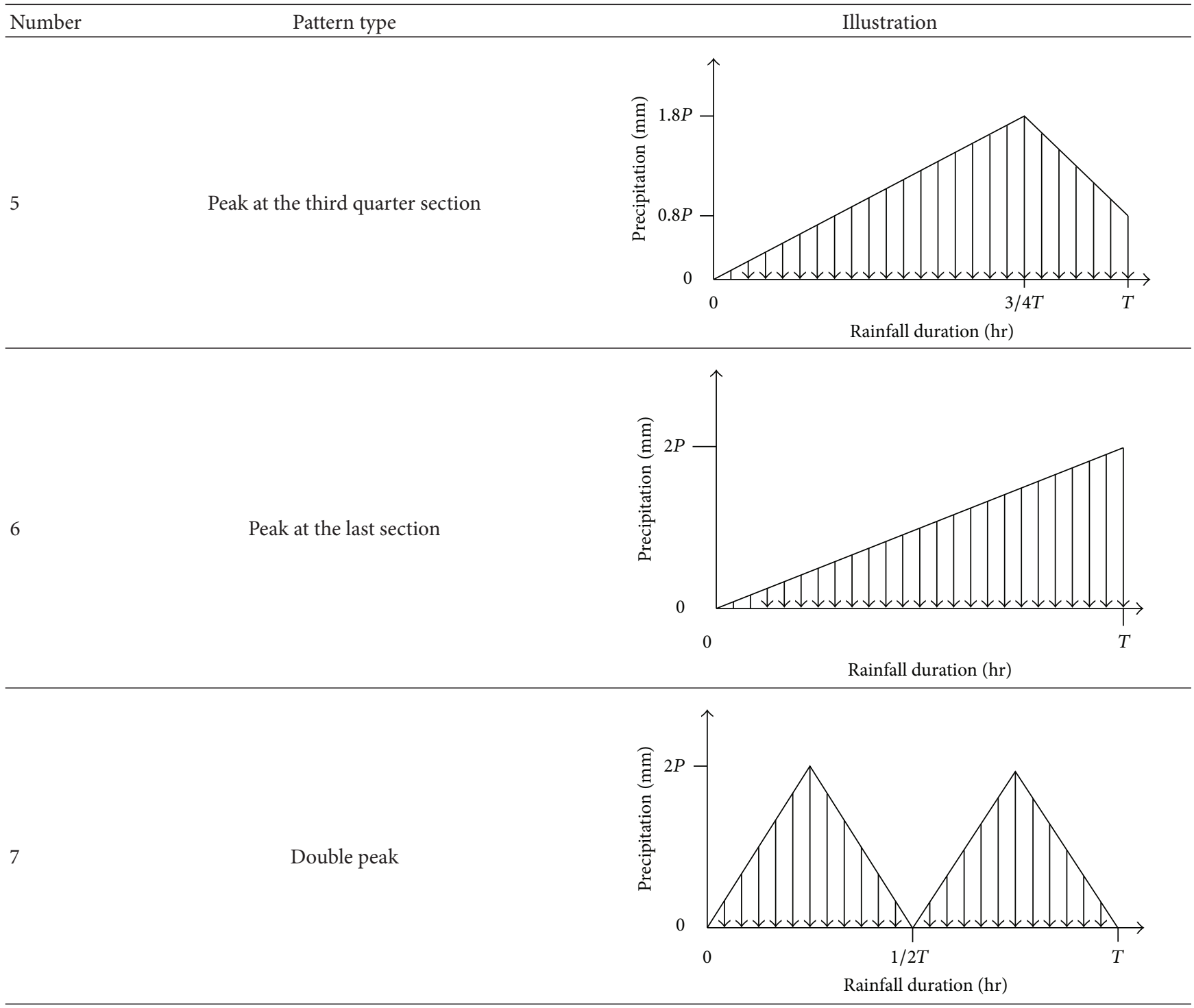

4.6. Reliability Analysis: First-Order Reliability Method (FORM). In the following, the reliability analysis evaluated by ANN-based FORM is illustrated using the same case. The $\beta$-ellipse technique carried out in a spreadsheet environment, such as Microsoft Excel, proposed by Low [14] is used in the analyses.

The results obtained by ANN-based FORM are also shown in Figure 8. Comparing the results of FORM with those of MCS, it can be found that the failure probability obtained from FORM is less than that obtained from MCS for small $P_{f}$ value, and their differences are larger if the design variables are following log-normal distribution, whereas the differences are minor if the design variables are following normal distribution. Therefore, the two method-ANN-based FORM and ANN-based MCS_can get comparable results with limit differences for variables with normal distribution based on this case study. Furthermore, whatever for which method, in comparison to results obtained from variables with different distributions, it can be found that $P_{f}$ with normal distribution (denoted by $P_{f \_N}$ ) are greater than those with log-normal distribution (denoted by $P_{f-L N}$ ), that is, $P_{f-N}>P_{f_{-L N}}$, especially when failure probability is smaller. Thus, in view of the evaluation efficiency and consideration of conservative design, the ANN-based FORM method with input variables of normal distribution will be adopted in the following analyses to explore the influence of rainfall characteristics on the reliability of MSW landfills on slope.

Figure 9 is the relationship between required factor of safety $\mathrm{FS}_{r}$ and failure probability $P_{f}$ for different rainfall intensity $I$ with rainfall duration $T=36 \mathrm{hr}$. Obviously, failure probability increases with rainfall intensity. For example, if $I=40 \mathrm{~mm} / \mathrm{hr}$, when $\mathrm{FS}_{r}$ increases from 1.0 to 1.2 , the associated $P_{f}$ increases vastly from 0.000086 to 0.003233 . The corresponding performance level will be from "above average" decreases to near "below average" according to the relationship of target reliability index and failure probability 
TABLE 3: The probable range considered for each parameter in the hypothetical site of MSW landfill.

\begin{tabular}{lcc}
\hline Parameter type & Name & Range \\
\hline \multirow{4}{*}{ Geometry parameter } & $H(\mathrm{~m})$ & $10 \sim 30$ \\
& $L(\mathrm{~m})$ & $10 \sim 50$ \\
& $\alpha\left(^{\circ}\right)$ & $30 \sim 75$ \\
$\beta\left(^{\circ}\right)$ & $15.95 \sim 60$ \\
\hline & $\gamma_{1}\left(\mathrm{kN} / \mathrm{m}^{3}\right)$ & $4.9 \sim 9.8$ \\
$\gamma_{2}\left(\mathrm{kN} / \mathrm{m}^{3}\right)$ & $18 \sim 22$ \\
& $\gamma_{3}\left(\mathrm{kN} / \mathrm{m}^{3}\right)$ & 24 \\
Material parameter & $c_{1}(\mathrm{kPa})$ & $33.55 \sim 34.90$ \\
& $c_{2}(\mathrm{kPa})$ & $0 \sim 0.7$ \\
& $c_{3}(\mathrm{kPa})$ & 245.25 \\
& $\phi_{1}\left(^{\circ}\right)$ & $10 \sim 40$ \\
& $\phi_{2}\left(^{\circ}\right)$ & $5 \sim 30$ \\
$\phi_{3}\left(^{\circ}\right)$ & 0 \\
\hline \multirow{5}{*}{ Rainfall parameter } & $I(\mathrm{~mm} / \mathrm{hr})$ & $0 \sim 100$ \\
& $T(\mathrm{hr})$ & $0 \sim 72$ \\
& Rainfall pattern & $1 \sim 7$ \\
\hline
\end{tabular}

TABLE 4: The statistical properties of the parameters for reliability analysis.

\begin{tabular}{lcccc}
\hline $\begin{array}{l}\text { Parameter } \\
\text { type }\end{array}$ & Name & Mean $(\mu) \begin{array}{c}\text { Coefficient } \\
\text { of variation } \\
(\mathrm{COV})\end{array}$ & $\begin{array}{c}\text { Standard } \\
\text { deviation } \\
(\sigma)\end{array}$ \\
\hline Geometry & $H(\mathrm{~m})$ & 20 & 0.01 & 0.2 \\
parameter & $\alpha\left(^{\circ}\right)$ & 60 & 0.01 & 0.3 \\
& $\beta\left(^{\circ}\right)$ & 30 & 0.01 & 0.6 \\
\hline \multirow{4}{*}{ Material } & $\gamma_{1}\left(\mathrm{kN} / \mathrm{m}^{3}\right)$ & 7 & 0.10 & 0.3 \\
parameter & $\gamma_{2}\left(\mathrm{kN} / \mathrm{m}^{3}\right)$ & 20 & 0.05 & 0.7 \\
& $c_{1}(\mathrm{kPa})$ & 34 & 0.20 & 6.8 \\
& $c_{2}(\mathrm{kPa})$ & 0.35 & 0.20 & 0.07 \\
& $\phi_{1}\left(^{\circ}\right)$ & 35 & 0.10 & 3.5 \\
Rainfall & $\phi_{2}\left({ }^{\circ}\right)$ & 23 & 0.10 & 2.3 \\
parameter & $I(\mathrm{~mm} / \mathrm{hr})$ & 50 & 0.02 & 1.0 \\
& $T(\mathrm{hr})$ & 36 & 0.01 & 0.36 \\
& $\mathrm{Rainfall}$ & $1 \sim 7$ & - & - \\
\hline
\end{tabular}

Subscript 1 stands for solid waste; subscript 2 stands for geomembrane.

suggested by U.S. Army Corps of Engineers [33]. Therefore, it is necessary to redesign the MSW landfills on slope to meet the performance requirements in this case. Thus, the reliability analyses will be beneficial to engineering design and provide a guideline to achieve the target reliability considering uncertainty.

Figure 10 is the relationship between $\mathrm{FS}_{r}$ and $P_{f}$ for different rainfall durations with rainfall intensity $I=50 \mathrm{~mm} / \mathrm{hr}$. As expected, $P_{f}$ increases with rainfall duration. Finally, Figure 11 is the relationship between rainfall pattern and $P_{f}$ for different mean rainfall intensities under the same total amount of precipitation with rainfall duration $T=36 \mathrm{hr}$ and

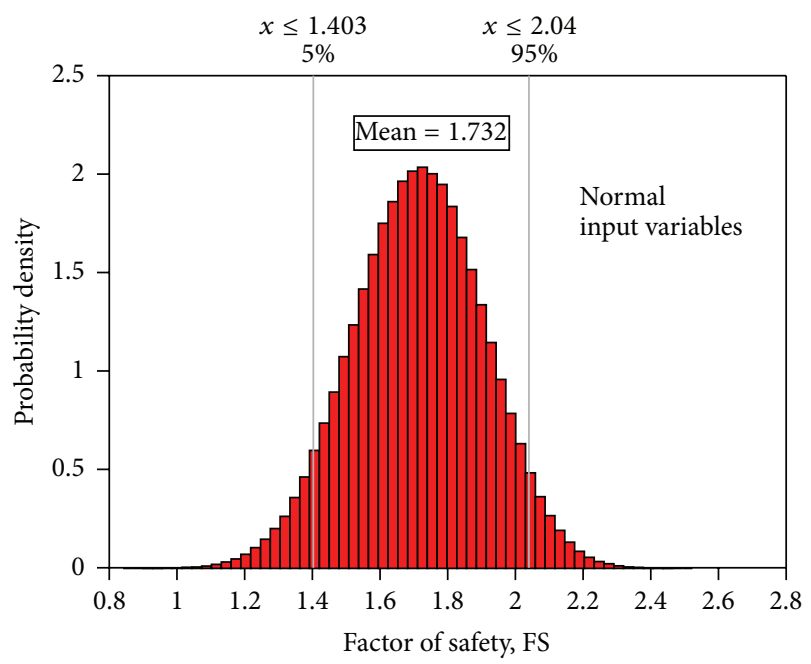

FIGURE 7: Histogram of factor of safety, FS, obtained from MCS assuming that the input variables are all following normal distribution and uniform rainfall pattern is adopted.

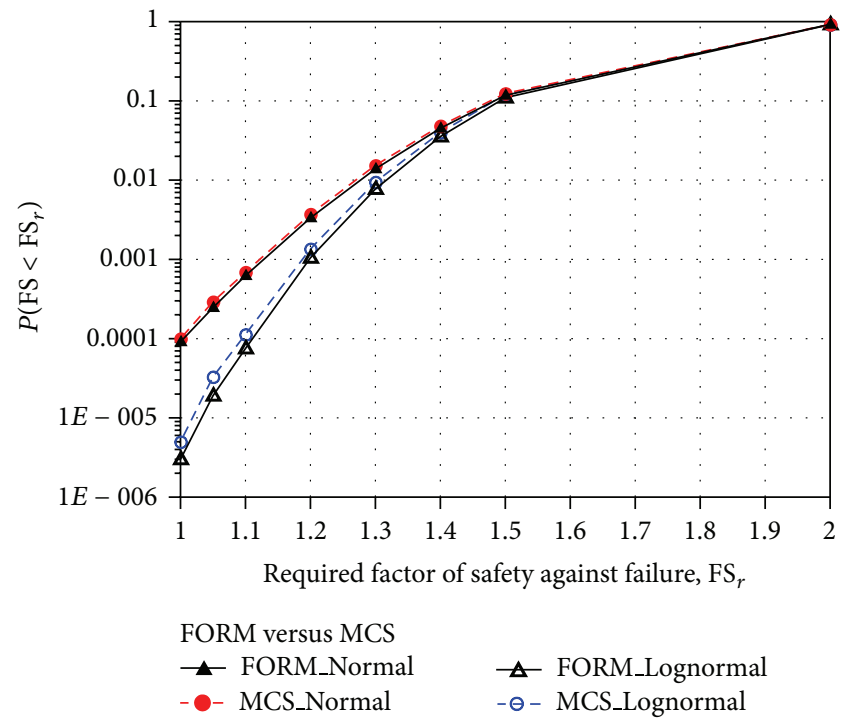

FIGURE 8: Comparisons of reliability analysis results between FORM method and MCS method.

$\mathrm{FS}_{r}=1.2$. It is shown that the Uniform pattern has the highest failure probability in the case. For other patterns, if the peak rainfall intensity occurs earlier, the cumulative amount of infiltrations will be larger with higher failure probability of $P_{f}$. The study of Jia et al. [34] draws similar conclusions and makes a recommendation that rainfall pattern should be taken into account in the performance assessment of landfill covers.

As to the effects of rainfall intensity and duration on the slope stability of MSW landfills and thus the failure probability, it can be attributed to the reduction in matrix suctions of unsaturated landfills and consequent fall in shear strengths caused by the rise in pore water pressures. The higher the rainfall intensity and/or duration, the lower the 


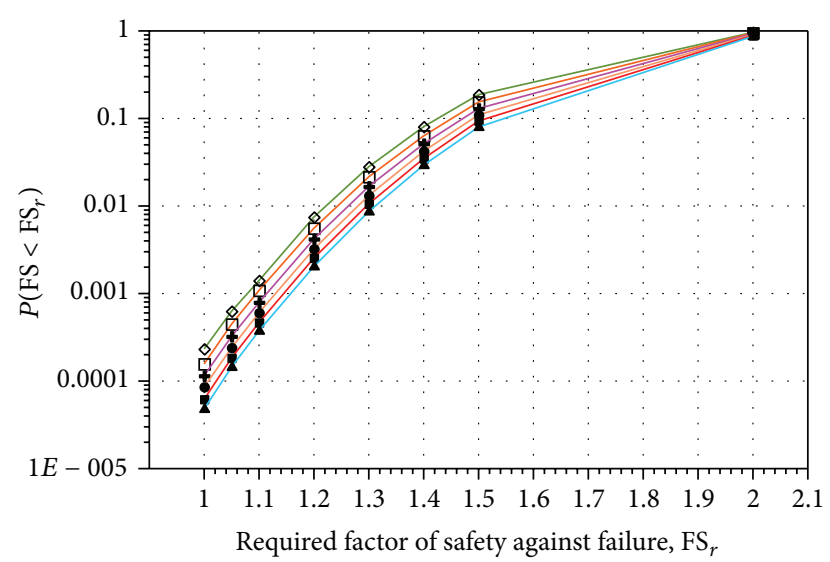

FORM

$$
\begin{aligned}
\diamond I(\mathrm{~mm} / \mathrm{hr}) & =100 & & -I(\mathrm{~mm} / \mathrm{hr})=40 \\
\square I(\mathrm{~mm} / \mathrm{hr}) & =80 & & -I(\mathrm{~mm} / \mathrm{hr})=20 \\
\leftarrow-I(\mathrm{~mm} / \mathrm{hr}) & =60 & & \leftarrow I(\mathrm{~mm} / \mathrm{hr})=0
\end{aligned}
$$

FIGURE 9: The relationship between required factor of safety and failure probability for different rainfall intensities $(T=36 \mathrm{hr})$.

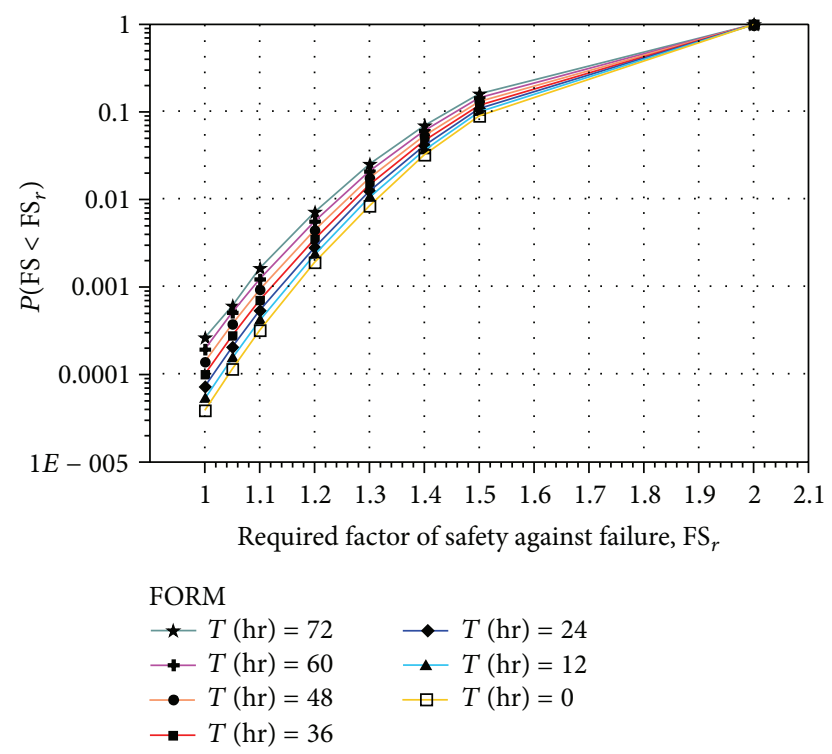

FIGURE 10: The relationship between required factor of safety and failure probability for different rainfall duration $(I=50 \mathrm{~mm} / \mathrm{hr})$.

matrix suctions behind the wetting front, and thus the higher the failure probability of the MSW landfills to be. The phenomena are the same as those studied by other researchers, such as $\mathrm{Ng}$ and Shi [35] and Li et al. [36].

\section{Conclusions}

In this study, two methods of reliability evaluation for the rainfall stability of MSW landfills on slope, ANN-based FORM and ANN-based MCS, are explored. By performing a case study of a hypothetical site, an analysis procedure for reliability analysis is proposed. The evaluation model of ANNbased FORM or ANN-based MCS is superior to traditional

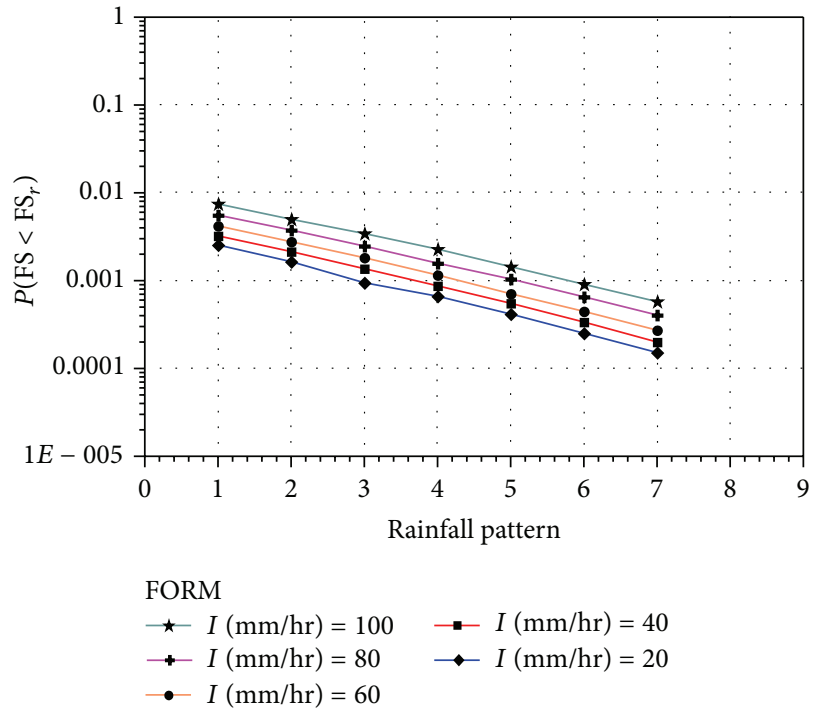

FIGURE 11: The relationship between rainfall pattern and failure probability for different rainfall intensities with $\mathrm{FS}_{r}=1.2(T=36 \mathrm{hr})$.

reliability method in view of many aspects, such as system modeling, computational efficiency, and analysis precision. Based on these methods, the performance-based design (PBD) of MSW landfills on slope can be implemented easily.

According to the analysis results, it can be concluded that all the rainfall characteristics, including intensity, duration, and pattern, have obvious influence on the reliability for stability of MSW landfills on slope. Thus, the variation of rainfall condition should be investigated and considered in the analysis. By the quantitative reliability method proposed in this study, it will be beneficial to MSW landfills design and provide a guideline to achieve the target reliability considering rainfall scenarios.

\section{Acknowledgment}

The authors would like to thank the anonymous referees for their valuable comments and suggestions on earlier drafts of this paper.

\section{References}

[1] D.G. Anderson and E. Kavazanjian, "Performance of landfills under seismic loading," in Proceedings of the 3rd International Conference on Recent Advances in Geotechnical Earthquake Engineering and Soil Dynamics, Rolla, Mo, USA, 1995.

[2] R. L. Anderson, "Earthquake related damage and landfill performance," Earthquake Design and Performance of Solid Waste Landfills, ASCE Geotechnical Special Publication, vol. 54, pp. 116, 1995.

[3] A. J. Augello, N. Matasovic, J. D. Bray E, Jr. Kavazanjian, and R. B. Seed, "Evaluation of solid waste landfill performance during the Northridge earthquake," Earthquake Design and Performance of Solid Waste Landfills, ASCE Geotechnical Special Publication, vol. 54, pp. 17-50, 1995. 
[4] I. M. Idriss, G. L. Fiegel, M. B. Hudson, P. K. Mundy, and R. Herzig, "Seismic response of the operating industries landfill," Earthquake Design and Performance of Solid Waste Landfills, ASCE Geotechnical Special Publication, vol. 54, pp. 83-118, 1995.

[5] E. Kavazanjian Jr. and N. Matasovic, "Seismic analysis of solid waste landfills," Geoenvironment 2000, V. 2, ASCE Geotechnical Special Publication, vol. 46, pp. 1066-1081, 1995.

[6] E. Kavazanjian Jr., N. Matasovic, R. Bonaparte, and G. R. Schmertmann, "Evaluation of MSW properties for seismic analysis," Geoenvironment 2000, V. 2, ASCE Geotechnical Special Publication, vol. 46, pp. 1126-1141.

[7] E. L. Krinitzsky, M. E. Hynes, and A. G. Franklin, "Earthquake safety evaluation of sanitary landfills," Engineering Geology, vol. 46, no. 2, pp. 143-156, 1997.

[8] P. S. S. Pinto, "Static and seismic analysis of solid waste landfills," in Proceedings of the International Symposium on Geoenvironmental Engineering (ISGE '09), Hangzhou, China, September 2009.

[9] N. Huvaj-Sarihan and T. D. Stark, "Back-analyses of landfill slope failures," in Proceedings of the 6th International Conference on Case Histories in Geotechnical Engineering, pp. 11-16, Arlington, Va, USA, August 2008.

[10] X. L. Liu, Study on stability of landfill due to rainfall infiltration [Ph.D. thesis], Tianjin University, Tianjin, China, 2006.

[11] H. D. Lin and C. P. Lin, "A preliminary study on resistance and load factors for drilled piles," Journal of the Chinese Institute of Civil and Hydraulic Engineering, vol. 11, no. 1, pp. 13-21, 1999.

[12] K. J. Shou and Y. L. Chen, "Spatial risk analysis of the Li-Shan landslide," in Proceedings of the 11th Conference on Current Researches in Geotechnical Engineering in Taiwan, pp. C04-4-C048, Wanli, Taiwan, September 2005.

[13] W. H. Tang, M. S. Yuceman, and A. H. S. Ang, "Reliability analysis and design of braced excavation systems," in Proceedings of the 1st International Conference on Applications of Statistics and Probability in Soil and Structural Engineering, pp. 187-202, Hong Kong, 1971.

[14] B. K. Low, "Reliability-based design applied to retaining walls," Geotechnique, vol. 55, no. 1, pp. 63-75, 2005.

[15] A. T. C. Goh and F. H. Kulhawy, "Neural network approach to model the limit state surface for reliability analysis," Canadian Geotechnical Journal, vol. 40, no. 6, pp. 1235-1244, 2003.

[16] A. H. S. Ang and W. H. Tang, Probability Concepts in Engineering Planning and Design. Decision, Risk and Reliability, Vol. II, John Wiley \& Sons, New York, NY, USA, 1984.

[17] O. Ditlevsen, Uncertainty Modeling: With Applications to Multidimensional Civil Engineering Systems, McGraw-Hill, New York, NY, USA, 1981.

[18] A. M. Hasofer and N. C. Lind, "An exact and invariant firstorder reliability format," Journal of Engineering Mechanics, vol. 100, no. 1, pp. 111-121, 1974.

[19] R. Rackwitz and B. Flessler, "Structural reliability under combined random load sequences," Computers and Structures, vol. 9, no. 5, pp. 489-494, 1978.

[20] K. Hornik, "Approximation capabilities of multilayer feedforward networks," Neural Networks, vol. 4, no. 2, pp. 251-257, 1991.

[21] G. P. Box and N. R. Draper, Empirical Model-Building and Response Surface, John Wiley \& Sons, New York, NY, USA, 1987.

[22] A. Bagchi, Design of Landfills and Integrated Solid Waste Management, John Wiley \& Sons, New Jersey, NJ, USA, 3rd edition, 2004.
[23] Taiwan Geotechnical Society, Design Code and Specifications of Building Foundations, 2001.

[24] Seepage Modeling with SEEP/W, GEO-SLOPE International Ltd., Alberta, Canada, 2004.

[25] Stability Modeling with SLOPE/W, GEO-SLOPE International Ltd., Alberta, Canada, 2004.

[26] Y. Y. Wang, Stability analysis of municipal solid waste landfills on slope [M.S. thesis], Department of Civil Engineering, National Chiao Tung University, Hsin-chu, Taiwan, 2007.

[27] G. B. Huang, Q. Y. Zhu, and C. K. Siew, "Extreme learning machine: theory and applications," Neurocomputing, vol. 70, no. 1-3, pp. 489-501, 2006.

[28] Y. Yuan, Y. Wang, and F. Cao, "Optimization approximation solution for regression problem based on extreme learning machine," Neurocomputing, vol. 74, pp. 2475-2482, 2011.

[29] Y. Wang, F. Cao, and Y. Yuan, "A study on effectiveness of extreme learning machine," Neurocomputing, vol. 74, pp. 24832490, 2011.

[30] K. K. Phoon and F. H. Kulhawy, "Characterization of geotechnical variability," Canadian Geotechnical Journal, vol. 36, no. 4, pp. 612-624, 1999.

[31] J. M. Duncan, "Factors of safety and reliability in geotechnical engineering," Journal of Geotechnical and Geoenvironmental Engineering, vol. 126, no. 4, pp. 307-316, 2000.

[32] M. L. Shooman, Probabilistic Reliability: An Engineering Approach, McGraw-Hill, New York, NY, USA, 1968.

[33] U.S. Army Corps of Engineers, Introduction to Probability and Reliability Methods for Use in Geotechnical Engineering, Engineering Technical Letter no. 1110-2-547, U.S. Army Corps of Engineers, Washington, DC, USA, 1995.

[34] G. W. Jia, T. L. T. Zhan, Y. M. Chen, and D. G. Fredlund, "Influence of rainfall pattern on the infiltration into landfill earthen final cover," in Proceedings of the International Symposium on Geoenvironmental Engineering, pp. 641-645, Hang-zhou, China, September 2009.

[35] C. W. W. Ng and Q. Shi, "A numerical investigation of the stability of unsaturated soil slopes subjected to transient seepage," Computers and Geotechnics, vol. 22, no. 1, pp. 1-28, 1998.

[36] W. C. Li, L. M. Lee, H. Cai, H. J. Li, F. C. Dai, and M.L. Wang, "Combined roles of saturated permeability and rainfall characteristics on surficial failure of homogeneous soil slope," Engineering Geology, vol. 153, pp. 105-113, 2013. 


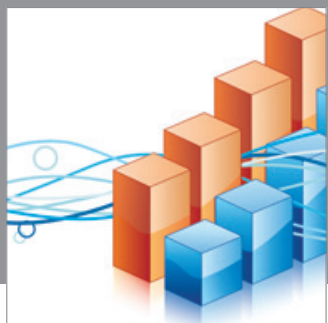

Advances in

Operations Research

mansans

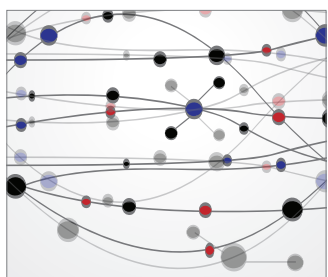

The Scientific World Journal
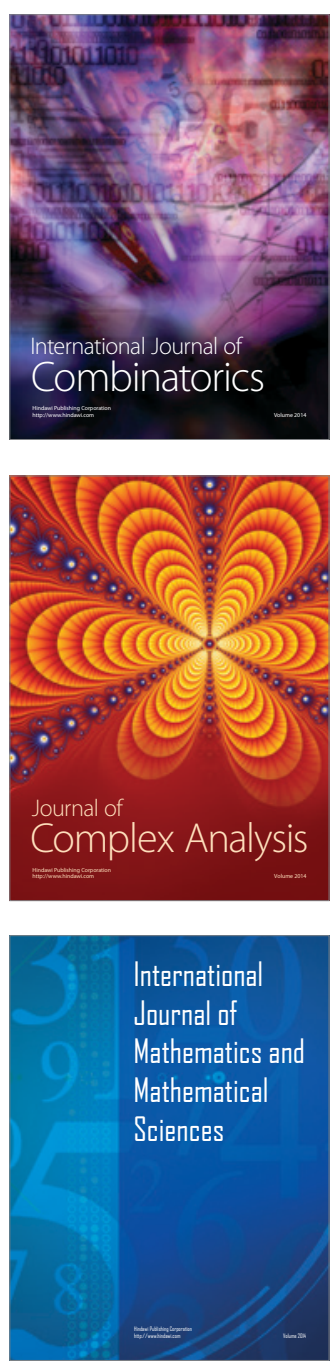
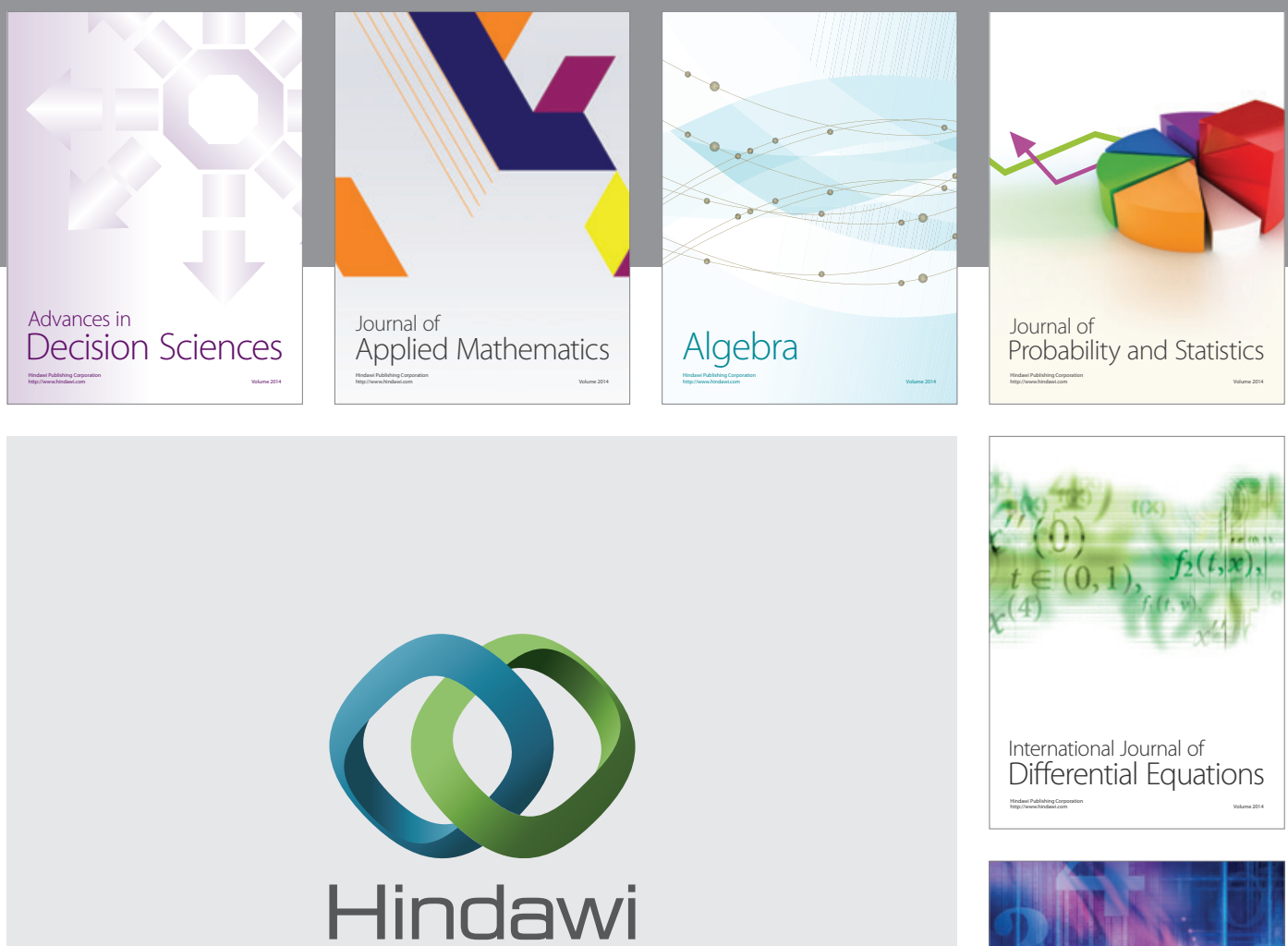

Submit your manuscripts at http://www.hindawi.com
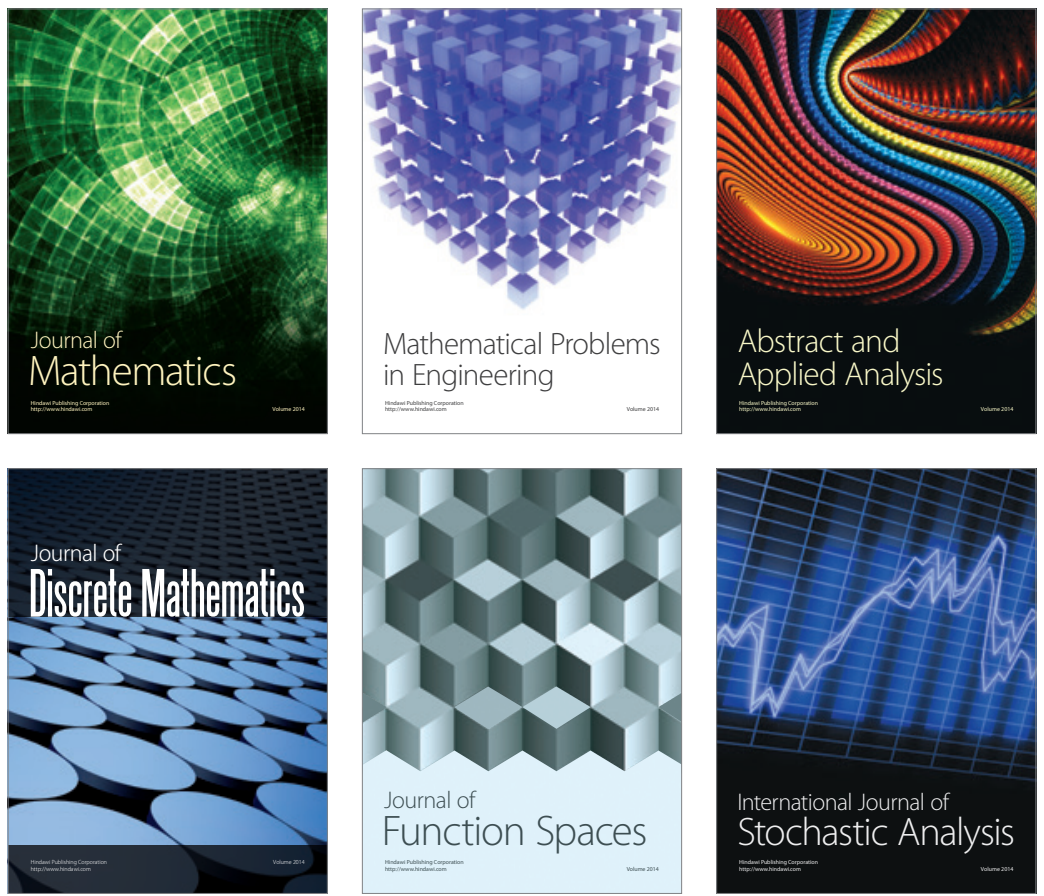

Journal of

Function Spaces

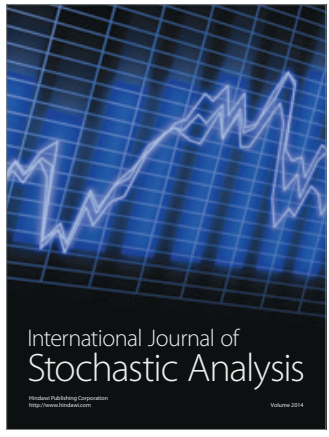

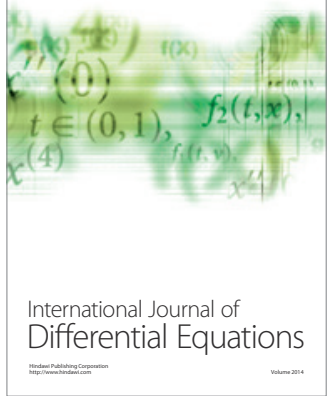
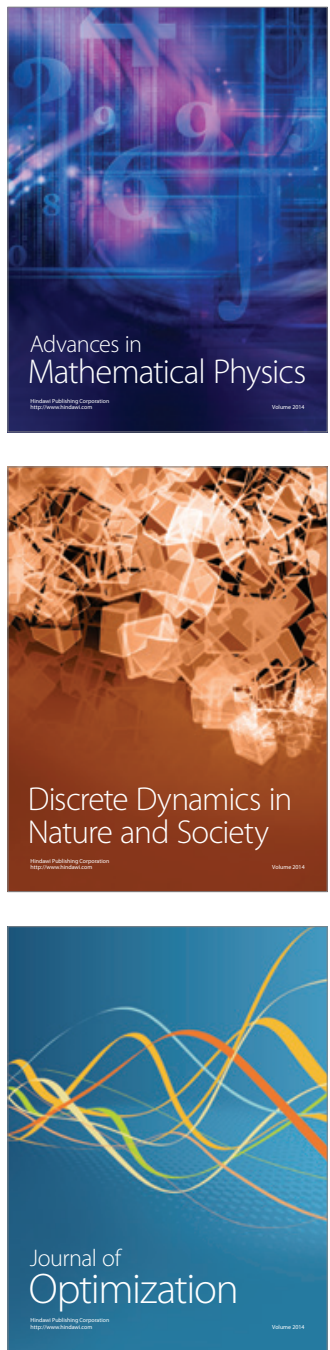